\title{
Histological Structure of the Kidney in the Iraqi Weasel, Small Asian Mangoose, (Herpestes Javanicus ) (E.Geoffroy Saint.Hilaire,1818)
}

\author{
Saddama Saed Faraj and Rana Alaa Al-Aamery \\ ${ }^{1}$ Biology Dep., Education College for Pure Sciences - Ibn Al- Haitham, Baghdad University, Iraq \\ (ssaddama@yahoo.com, alameryrana@gmail.com)
}

\begin{abstract}
The present study aims to describe the histological structure of kidney of, (Herpestes javanicus ) that inhabits Iraqi lands. Transverse sections of kidney stained with hematoxylin and eosin showed two distinct regions, the outer thin darkly stained cortex and inner thick lightly stained medulla, which further subdivided into external and internal medullary zones linked with one conical renal papilla. The lateral margin of the outer medullary tissue forms a secondary renal pyramid with a specialized fornix. All the nephrons in the kidney start with the renal corpuscle [Malpighian], which is formed from two distinct parts, these are a centrally located glomerulus, which represented by a tuft of blood capillaries and an outer Bowman's capsule which is distinguished by its cup structure that lined by a double thin epithelial layers of flattened squamous cells with urinary space separated between them. The epithelial cells of the Proximal and distal convoluted tubules have cuboidal shape but in the first tubules these cells are characterized by the presence of moderate to tall microvilli formed the brush border covering the luminal surface.

Thin segment lined with flattened cells and found in large number in the medulla interna which indicate the presence of many nephrons with long loops of Henle. Well-developed vascular network was observed in the kidney tissue and a small to medium vascular bundles of vasa recta distributed in alternative fashion with uriniferous tubule bundles in the medulla externa. The terminal portion of papilla is lined externally by transitional epithelium which progressively towards the upper portion was changed first to simple cuboidal and then to flattened type.
\end{abstract}

Keywords: Kidney, Weasel, (Herpestes javanicus ), Histology.

\section{Introduction}

The mammalian kidney is highly vascular organ of the urinary system that participates in the removing of metabolic wastes from the body and controls the volume, and concentration of the body fluids, kidney also regulates the acid base balance and has an important endocrine function via production of renin, a substance that regulates the blood pressure and erythropoietin that stimulates the erythrocyte formation in the red bone marrow. $[9,15]$. Nephrons represent the basic structural and functional units of the kidney which perform the regulatory and excretory functions by multiple step process including filtration, reabsorption, and secretion $[9,15]$. There are little researches has been carried out on the morphology and histology features of kidney in the Iraqi mammalian species such as Buffaloes [16 ] dogs [4], one humped camel [5] and jerboa [7], and according to our knowledge no study has been achieved to describe the histological structure of the kidney in Weasel, Small asian mangoose (Herpestes javanicus ) (E.Geoffroy saint.Hilaire,1818), one of the Iraqi wild vertebrates, belongs to the family of Herpestidae, and the order of Carnivora. [4], therefore; the main goal of this work to provide information about the histological features of kidney in this animal to form the basic data for further studies in the future of the urinary system in this type of wild animals which is widely distributed along the Tigris and Euphrates rivers from Bashara to Zeban and recorded in many sites of Iraqi marshes[4]. 


\section{Materials and Methods}

Four mature weasel of both sexes [males and females] were used in this study which collected by the hunter from Al-Najaf Province. The animals were sacrificed under anesthesia with diethyl ether. Kidneys were removed and small pieces from the left and right kidneys were immediately fixed in $10 \%$ formalin for 24 hours at room temperature. Dehydration performed by immersion these pieces in containers contained ascending serial solutions of ethyl alcohol [70\%, 80\%, 90\%, and 100\%] and later were cleared with xylene. After that, they were embedded in paraffin. Sections of $5 \mu \mathrm{m}$ thickness were cut with the rotary microtome and stained with hematoxylin and eosin. All methods used in the preparation of the histological sections were applied according to [6]. Finally, the stained sections were examined by light microscope [Olympus; Japan]. Microphotographs were taken with a camera mounted on the light and dissecting microscopes.

\section{Results and Discussion}

In the weasel, kidney was covered with a thin capsule of dense regular connective tissue that composed mainly of bundles of collagen fibers and few reticular fibers and contains blood vessels rich with erythrocytes [Fig.1A,], and such a finding is on the line with [2] in white rabbit female and [2] in Iraqi Jerboa but in contrast with [17] who documented that the kidneys in Marwari sheep were invested by a thick fibrous capsule. Previous studies in the kidney of albino rat [3] and in Bactrian camel [11] indicated a distinct layer of smooth muscle fibers in the deepest portion of the renal capsule, while in the current work the renal capsule of weasel was free of smooth muscle fibers. Furthermore, at the hilar region and sides of the kidney, this capsule slightly decreased in thickness and their dense connective tissue changed to the loose type and surrounded by a mass of fatty tissue primarily composed of a yellow adipose type with little brown adipose type [Fig. 1A, B,2]. This finding partial agreement with the study performed by [12], who reported that a dense layer of a yellow adipose tissue with scanty loose irregular connective tissue fibers was found at the hilum of the kidney in palm squirrel. This variation in thickness and structure of renal capsule among species suggest that it could play a certain role in renal function. Numerous large blood vessels filled with blood were observed directly under the capsule and extended into the cortex [Fig2]. According to [14]. Well-developed vascular network on the whole kidney surface increased the transportation of substances across the kidneys, which may be considered as an adaptation for the feeding habits of the carnivorous animals.

Like other mammals, kidney of the studied species was consisting of two distinct regions: the outer, darkly stained cortex which is present underneath the capsule, and lighter coloured region, called the medulla which occupied the central part of the kidney [Fig2, 3]. The medullary tissue formed a large part of kidney parenchymal tissue when compared to the cortical tissue and further subdivided into an outer and an inner zone that leads to a single, distinct, conical papilla which was not protruding outside parenchymal tissue of kidney [Fig3], such observation was mentioned by [14,10]. The presence of thick medullary tissue in the kidney of weasel suggests that it has a great ability to concentrate urine. The lateral margin of the outer medullary tissue extended into the pelvic cavity to form a secondary pyramid with a specialized fornix extend deeply between the outer medulla zone and cortex [Fig 3,4]. In Bactrian camel, [19] reported that the secondary renal pyramid in kidney lateral edge was particularly obvious. The medullary rays invade about two thirds of the cortical tissue and none reach to the capsule surface[Fig2,6], as in our study [5] reported that the medullary rays project to the outer cortex region but not extend to the capsule surface in the kidney of West Indian Manatee. Our study also showed that the medullary rays consisted of straight portions of uriniferous tubules as well as cortical collecting tubules. The corticomedullary junction is characterized by the presence of conspicuous arcuate vessels [arteries and veins] [Fig.4,5,6]. In Bactrian camel, [19] found that vascular bundles of vasa recta distributed in alternative pattern with the uriniferous tubules bundles in the outer medullary zone and their width was nearly equal to that of bundle while in the current work these bundles appear small or medium in size and all them were smaller than the uriniferous tubules bundles, and this suggests that kidney in weasel may less efficient in concentrate urine than kidney in Bactrian camel. Similar to previous studies achieved in many mammalian 
species $[1,2,17,140]$, the transverse sections showed that the Parenchymal substance of kidney consisted of nephrons which are formed the structural units of the kidney and each of them constituted from renal corpuscle and renal tubule that composed of a proximal and distal convoluted tubule, and a loop of Henle which connected between the straight portions of them.

\section{Bowman's Capsule and Glomerulus}

Renal corpuscles appear as spherical or slightly flattened oval structures [Fig. 2,7] and similar to the data indicated by [1] in jerboa and by [7] in dogs, their quantity was less in the superficial region of the cortical labyrinth than that of the of mid-cortical and juxtamedullary regions[Fig.2,6]. The study of [19] in the kidney of the Bactrian camel recorded that renal corpuscles were absent below the capsule in the range of 1000 to $1500 \mu \mathrm{m}$ while in the current work we observed some of the renal corpuscles are present directly below the capsule in the hilar region [ Fig. 1B]. This result suggests that more filtration process occurred in this region. Microscopic analysis also showed that these corpuscles were varied in size and most of the large renal corpuscles present in the mid-cortical region and juxtamedullary region, close to the medulla [ Fig. 2,6]. The renal corpuscle in weasel is formed by two distinct parts, these are a centrally located, glomerulus, and an outer Bowman's capsule which is distinguished by its cup structure that lined by a double thin epithelial layers [Fig1B,7], an outer parietal layer and an inner visceral layer which are separated from each other by patent urinary space. The parietal layer lined by one row of flattened, squamous epithelial cells supported by prominent basal lamina and contain dark nuclei plugging towards the urinary space. The visceral layer closely envelops the glomerular capillaries and lined with a modified squamous epithelial cells named podocytes. The glomerulus consists of a network of densely packed anastomosing capillaries surrounding a central core of basophilic mesangial cells which contain small, rounded nuclei stained darkly with hematoxylin. The cells of macula densa were seen in the vascular pole of the Malpighian corpuscles associated with the distal convoluted tubule. It appears as single layered of high cuboidal and tightly packed cells with darkly stained cytoplasm and elliptical, to oval nuclei which were stained lightly with hematoxylin [Fig.7], like that reported by [17] in the kidney of Marwari sheep.

\section{Proximal Convoluted Tubule (PCT)}

This tubule represents the first portion of the uriniferous tubule and appeared more frequently in transverse sections passing through the cortex than the distal convoluted tubules [Fig1B, 7], and this suggests that it was longer than the second tubule type. The lining epithelial cells of these tubules were high cuboidal resting on visible basal lamina with indefinite border cells, and their apical surfaces were covered by moderate to tall microvilli, the brush border, which projects into the narrow, irregular lumen. The proximal convoluted tubule is the major site responsible for reabsorption of more than two thirds of electrolyte and water. The existence of well growth brush border may enhance the reabsorptive capacity of these tubules for the fluids and glomerular filtrate. The nuclei were large, spherical to elliptical in shape and stained lightly with hematoxylin and each one of them have one or two prominent nucleoli. These nuclei usually occupied the basal part of the cells but in some of the cells, they were positioned either central or toward the apical portion of cells. The cytoplasm appeared granular and intensely stained with eosin and these results were in the line of [2] who reported that the proximal convoluted tubules of the kidney in rabbit female were formed by tall cuboidal epithelial cells possess round to elliptical nuclei in the deeply stained eosinophilic cytoplasm.

\section{Loop of Henle}

The present work revealed that the loop of Henle in the kidney of weasel consists of two distinct structures: the thick and the thin segment. The wall of the thin segment of the loop of Henle was thin and surrounded a narrow lumen. It was composed of a single layer of squamous cells with rounded to slightly flattened nuclei that may project towards the lumen and stained deeply with hematoxylin [Fig. 8]. This description of the thin segment of the Henle in agreement with the finding of [1] in Iraqi Jerboa. Numerous sections of thin segments of Henle's loops were seen in the inner medulla zone of the kidney and this indicated that there were many 
nephrons with long loops are present in the kidney of a weasel which were a prerequisite for the production more concentrated urine in the arid and semi-arid environments. A similar observation was recorded by [13] in long-eared hedgehogs and by [19] in Bactrian camel. The thick segments of the loop of Henle had clear circular lumina, lined by one layer of low cuboidal cells [Fig.8] which was similar to that recorded by [17] in Marwari sheep and by [3] in albino rats. The cytoplasm of thick segment cells appeared homogenous and stained less intensely with eosin than that in the proximal convoluted tubule. The nuclei are spherical to slightly flattened and generally situated near the surface membrane of the cell. Individual or Bundles of blood vessels engorged with blood were noticed adjacent to or between the loops of Henle [Fig. 7,8].

\section{Distal Convoluted Tubule [ DCT]}

The DCT had a clearly defined lumen and are lined by one row of low cuboidal epithelial cells rested on visible basal Lamina. The boundaries of these cells were indistinct and the apical surface free of brush border. In cross sections, these cells appeared lower and less acidophilic than those present in the PCT. The nuclei of these cells were spherical and occupied a central to apical position [Fig.1B,7]. This finding is in parallel with [7] in dogs who stated that the distal convoluted tubule lined by simple cuboidal epithelium, the brush border absents in its cells which are smaller and lighter than those in the proximal convoluted tubule. but in contrast with [10] who observed that the distal convoluted tubules were lined by low columnar cells in the kidney of four toad jerboa.

\section{Collecting Tubules and Ducts}

Cells that lining of the collecting tubules in the medullary rays and outer medullary zone are of simple a cuboidal type of epithelium, these cells had granular, pink coloured cytoplasm and showed well-demarcated cell boundaries which can be easily distinguished under the light microscope. The nuclei were large spherical or slightly flattened, located in the center or towards the apices of cells[Fig8]. Such observation also recorded in the kidney of the fat sand rat by [10] who stated that the collecting tubule in the outer medulla was made up by cuboidal cells with rounded nuclei in the slightly basophilic cytoplasm. The current study also revealed that the epithelium of the collecting tubules abruptly changed from cuboidal to flattened shape of cells when these tubules pass into the inner medullary zone, in addition, their cytoplasm less accepted staining and appeared paler with few or free of granules [Fig 9], these results were constant to the finding of [8]. in the chinchilla' kidney but in contrast with [18] who reported that the change in the shape of cells and the staining property occurred in the outer zone of the medulla.

Collecting ducts formed by high cuboidal epithelial cells in which the rounded vesicular nuclei almost are positioned near the luminal surface of the cells and surrounded by paler cytoplasm [Fig10]. As these ducts progress through the medullary tissue towards their openings in the tip of papilla [area cribrosa], they merge to form larger collecting ducts [ducts of Bellini], and their lining epithelium gradually changes from cubic to transitional type near the apex of the papilla. [Fig.10] In contrast, the study achieved by [3] in albino rat demonstrated that the terminal portion of these ducts [ducts of Bellini] is lined with simple columnar or pseudostratified epithelial tissue. [1] found that the papillary ducts lined by tall columnar epithelium cells in terminal portion of the medullary region in the kidney of the Iraqi Jerboa and gradually altered into transitional near renal papilla. A large number of wide blood capillaries engorged with erythrocytes were seen distributing among the collecting tubules and ducts in the inner medullary zone.

The external surface of the tip of the renal papilla was covered by transitional epithelium. As this covering epithelium progresses to cover the upper part of the medullary region, it changes gradually from transitional epithelium to simple cuboidal epithelium and then to flattened epithelium [Fig9, 10]. In Marwari sheep [17] was also observed that the renal papilla was lined by transitional epithelium. 


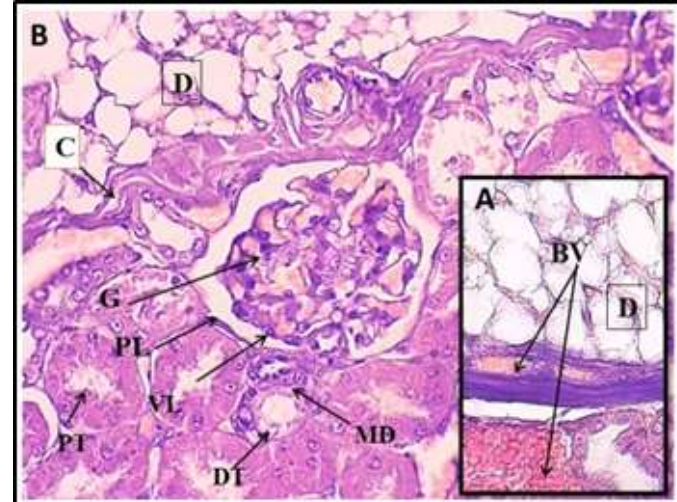

Figure (1) A - Cross section in the kidney of Herpestes javanicus showing dense collagenous fibrous capsule (C), adipose tissue(D) , blood vessels (BV). (H\&E.X400) B- Cross section through cortex showing capsule (C),adipose tissue (D) , parietal (PL) and visceral layer(VL) of renal corpuscle, glomerulus (G), distal (DT) and proximal convoluted (PT) tubules (H\&E.X400)

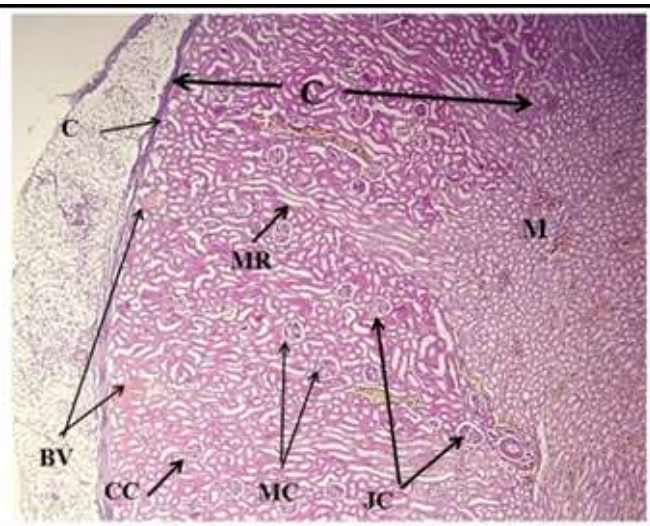

Figure (2) Cross section in the kidney of Herpestes javanicus showing capsule $(\mathrm{C})$, cortex $(\mathrm{CO})$, cortical renal corpuscle (CC), midcortical renal corpuscle (MC) , juxtamedullary renal corpuscle (JC), medullary rays (MR ), blood vessels (BV), medulla(M),(H\&E.X40)

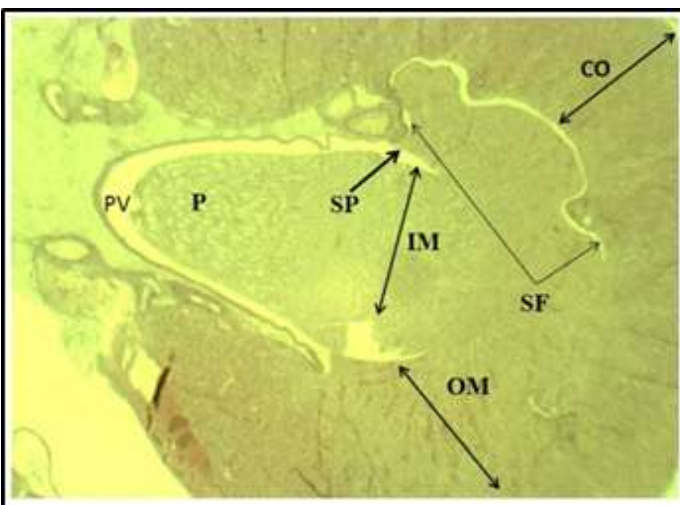

Figure (3) Cross section in the kidney of Herpestes javanicus showing the capsule $(\mathrm{C})$, cortex $(\mathrm{CO})$, outer medullary zone $(\mathrm{OM})$, inner medulla zone (IM), renal papilla $(\mathrm{P})$, pelvic cavity (PV), secondary renal pyramid (SP), specialized fornix (SF), (H\&E,X20)

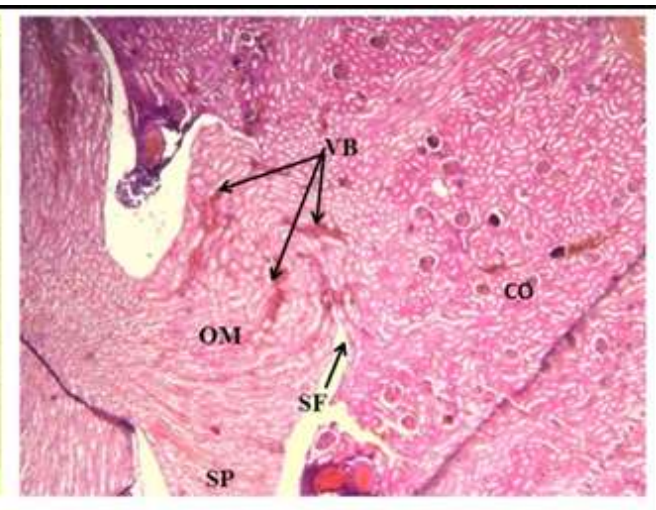

Figure (4) Cross section in kidney showing cortex (CO), outer medullary zone (OM ), inner medulla zone (IM), Secondary renal pyramid (SP), specialized fornix (SF),

Vascular bundle of vasa rectae (VB) (H\&E.X40)

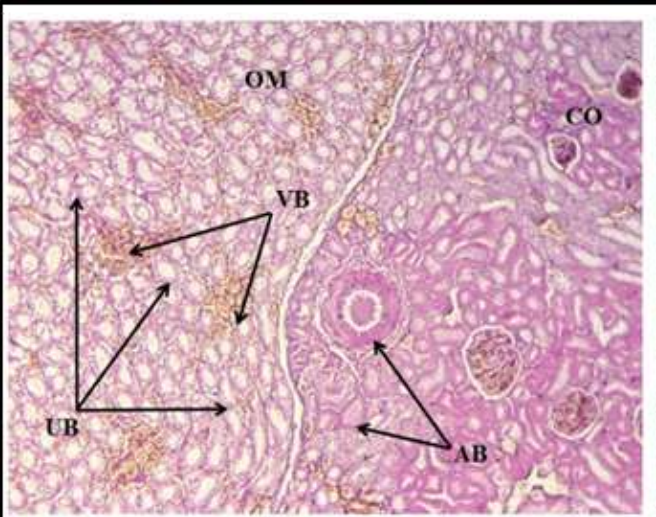

Figure (5) Cross section in the kidney of Herpestes javanicus showing cortex $(\mathrm{CO})$, outer medullary zone (OM) arcuate blood vessels (AB), vascular bundle of vasa rectae (VB), uriniferous tubule bundle ( UB) (H\&E.X100)

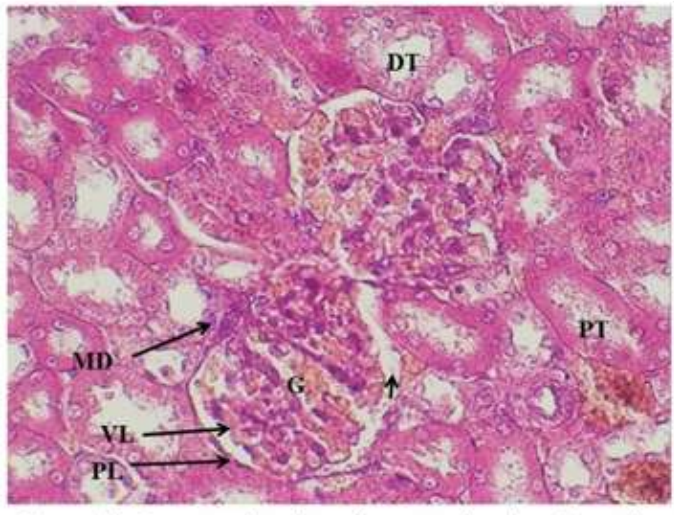

Figure (6) Cross section through cortex showing glomerulus (G), parietal layer (PL) and visceral layer (VL) of Bowman's capsule, urinary space (short arrow), macula densa (MD), proximal convoluted tubule (PT), distal convoluted tubule (DT) , (H\&E.X400) 

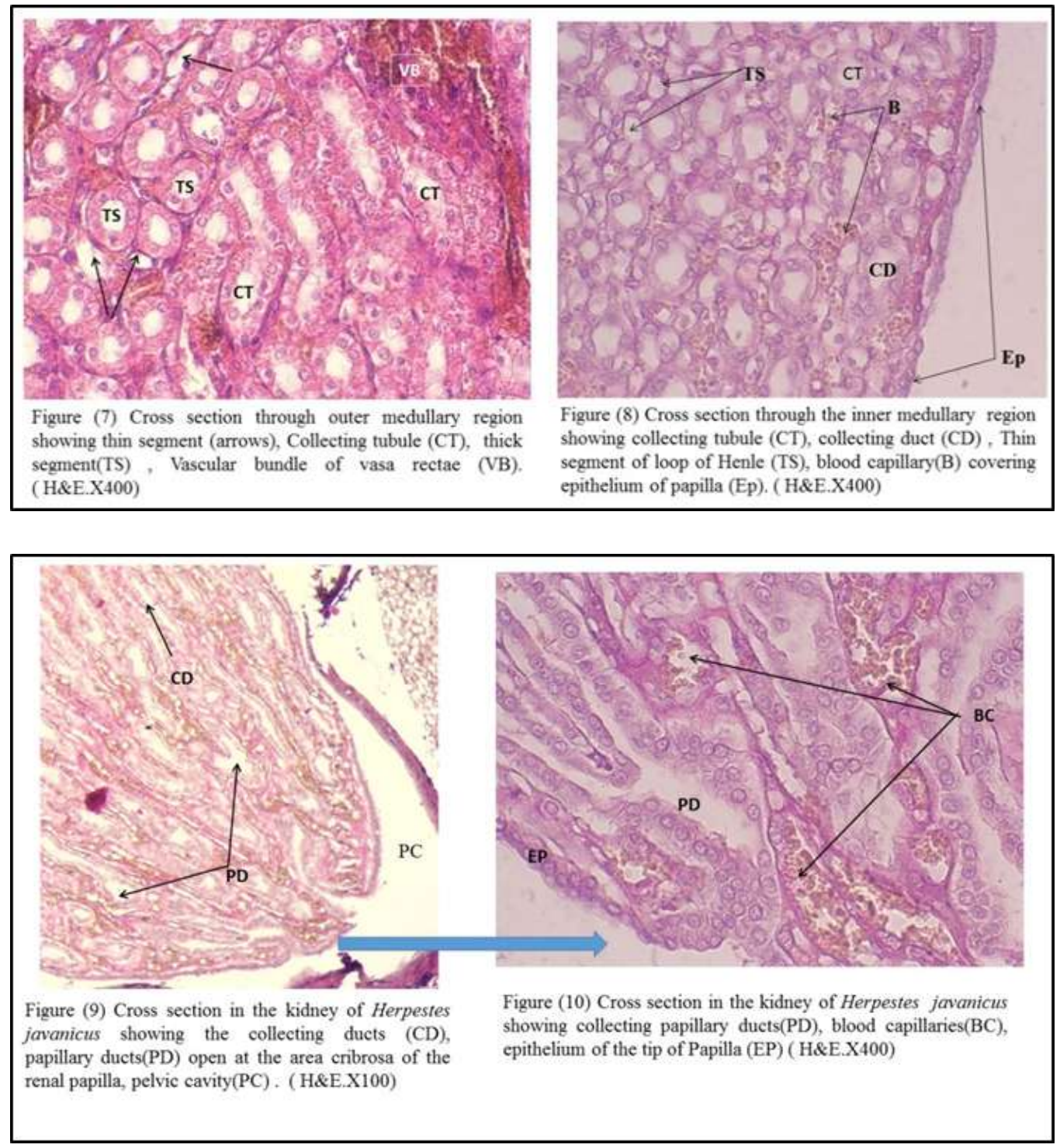

\section{References}

[1] Al-jebori, A. K. H [2016]. Histomorphplogical study of kidney in Iraqi jerboa [Jaculus jaculus] Euphrates Journal of Agriculture Science-8 [3]: $69-82$.

[2] Al-Jeboril, J.G.A.; Al-Badri, A.M.S. and Jassim, B.A. [2014]. Study of the anatomical and histomorphological description of the kidney in adult white rabbits female "New Zealand strain". world J. Pharm. Pharma. Sci., 3[6]:40-51.

[3] Al-Samawy, E.R.M. [2012]. Morphological and histological study of the kidneys on the Albino rats. Al-Anbar J Vet Sci., 5[1]:115-119.

[4] Al-Sheikhly, O F.; Haba, M. K.; Barbanera, F.; Csorba, G. and Harrison, D. L. (2015). Checklist of the Mammals of Iraq (Chordata: Mammalia). Bonn. zool. Bull., 64 (1): 33-58.

[5] Ashley, J. and Reynolds, I. [1989]. Gross and microscopic anatomy of the kidney of West Indian Manatee. Trichechus manatas [Mammalian:Sirenia]. Act. anat.135:53-56.

[6] Bancroft, J. D., and M. Gamble, 2002: Theory and Practice of Histological Techniques, 5th edn. New York: Churchill Livingstone, pp. 181-182.

[7] Baragoth AF; Ghazi, H.A. AbdZaid, K. [2014] Histological study to the nephrons of the kidney in Dogs [Canisfamiliaris] in midlle of Iraq Kufa J. Vet. Med. Sci., 5 [1]:98-103. 
[8] Braun, E. J. [1965]. The gross and microscopic renal anatomy of the fish eating bat, Pizonyx vivesi, M.Sc. thesis, The graduate collage, University of Arizona, United states of America.

[9] Dellmann, H. D. [1993]. Textbook of Veterinary histology. $3^{\text {rd }}$ Ed. Lea and Febiger, Philadelphia. PP: 210-220.

[10] El- Salkh B. A.; Zaki T. Z.; Basuony; M. I. and Khidr, H. A. [2008] Anatomical, histological and histochemical studies on some organs of true desert rodents in The Egyptian Habitats. The Egyp. J. of Hosp. Med., 33: 578- 306.

[11] Hussin, A.M., [2003]. Seasonal Histological changes in kidney of one humped camel Camelus dromedarius in middle of Iraq. M.Sc. thesis Vet. Medicine College, University of Baghdad. Baghdad, Iraq.

[12] Ikpegbu, E., U.C.; Nlebedum,U. and Ibe C.S., [2014]. The kidney and adrenal gland of the African palm squirrel Epixerus ebii: A microanatomical observation. Rev. Fac. Cs. Vet., 55: 60-67.

[13] Nabipour A, Dehghani H. Light and electron microscopic features of the kidney in hedgehog [Hemiechinus auritus]. J Vet Anat. 2012; 5[1]: 91-106.

[14] Patil K. G., Janbandhu, K.S.; Shende V. A.; Ramteke A. V. and Patil M. K. [2016] Adaptations in the kidney of Palm Civet, Paradoxurus hermaphroditus [Schrater], Inter. J. of Life Sci., 4[2]: 198-202.

[15] Patton, K. T. and Thibodeau, G. A. (2014) The Human Body in Health \& Disease - E-Book $6^{\text {th }}$ ed. St louis, Missouri, Elsevier printed in Canada. pp532 -574.

[16] Sawad, A. A. [2006]. Functional anatomy of the kidney in the Buffaloes.Bas.J.Vet.Res.,5[2]:76-82.

[17] Singh, A.K. [2013]. Gross and histological studies of the kidney in Marwari sheep [Ovis aries] M.Sc. Thesis, College of Veterinary and Animal Science, Rajasthan University of Veterinary and Animal Sciences, Bikaner, Rajasthan).

[18] Wright, D.V. [1969]. Observations on the gross and histological morphology of the chinchilla kidney M. Sc. thesis, The Graduate College, University of Arizona.

[19] Xu C-S; Bao, H-J; Qi, F-H; Liu, Y, Qin, J-H; Gandahi1, J A; Chen, Q-S. [2009] Morpho-histological investigation of kidney of Bactrian camel [Camelus bactrianu]: J. Camel Practice and Reserch, 16 [2]: 1-6. 